\title{
Calculation of two-electron reduction potentials for some quinone derivatives in aqueous solution using Møller-Plesset perturbation theory
}

\author{
Mansoor Namazian $^{\mathrm{a}, *}$, Samira Siahrostami ${ }^{\mathrm{a}}$, Mohammad R. Noorbala ${ }^{\mathrm{a}}$, Michelle L. Coote ${ }^{\mathrm{b}}$ \\ ${ }^{a}$ Department of Chemistry, Yazd University, Yazd P.O. Box 89195-741, Iran \\ ${ }^{\mathrm{b}}$ Research School of Chemistry, Australian National University, Canberra ACT 0200, Australia
}

Received 28 October 2005; received in revised form 8 November 2005; accepted 9 November 2005

Available online 10 January 2006

\begin{abstract}
Møller-Plesset perturbation theory at the level of third order (MP3) is used to compute two-electron reduction potentials for some substituted benzoquinones in aqueous solution. The calculations are carried out at the MP2 and MP3 levels with the use of continuum solvation method of PCM to mimic to role of solvent. Emphasis is placed on the use of two and third corrections of gas-phase energies. This model also gives electrode potential values in agreement with the experimental results.
\end{abstract}

(C) 2005 Elsevier B.V. All rights reserved.

Keywords: Electrode potentials; Perturbation theory; MP2; MP3; Benzoquinones

\section{Introduction}

The propensity of a molecule to donate or accept an electron in solution is measured by its standard redox potential and knowledge of standard redox potential is fundamental to understanding the chemical and biological electron-transfer reactions [1-3]. Quinones are important naturally occurring pigments that are widely distributed in nature and are known to demonstrate various physiological activities as antibiotics and anti-cancer agents due to their electrochemical properties [4]. Detailed theoretical studies of electron transfer reaction of quinone derivatives have been reported recently [2,5-11]. Although the calculations gave theoretical values in agreement with the experimental results to some extent, more studies are necessary in order to reduce the discrepancy between theory and experiment. Recently, we have reported the calculated two-electron reduction potentials $\left(E_{2}^{\circ}\right)$ of a limited number of quinone derivatives in aqueous solution $[12,13]$. The calculations were performed using Hartree-Fock (HF) and density functional theory (DFT) with solvation treated with polarisable continuum model (PCM or Tomasi model of solvation).

In this article, we examine a higher level of theory to improve the HF energies. The Møller-Plesset perturbation

\footnotetext{
* Corresponding author.

E-mail address: namazian@yazduni.ac.ir (M. Namazian).
}

theory at the level of third order (MP3) [14,15] has been employed in order to compensate the HF deficiency concerning electron correlation. The results have been found to be improved and the discrepancy between theory and experiment decreased to $0.019 \mathrm{~V}$.

\section{Methods and theoretical considerations}

In order to calculate the absolute equilibrium reduction free energy, either generation or consumption of the free electron should be considered. In practice, however, free electrons are not actual participants in most reactions. Instead, the electrons are consumed, or generated, respectively, by another halfreaction [2]. The standard hydrogen electrode (SHE) is a useful reference for putting the oxidation and reduction potentials on a convenient scale. Where the goal is to understand the variation in redox potentials over a series of chemically similar substances, an alternative is relying on cancellation of errors in the computation of relative redox potentials within the series $[2,5]$. In this case, an isodesmic reaction such as reaction (1) is helpful:

$\mathrm{Q}_{\text {(sol) }}+\mathrm{RH}_{2 \text { (sol) }} \rightarrow \mathrm{QH}_{2 \text { (sol) }}+\mathrm{R}_{\text {(sol) }}$

A substituted quinone $(\mathrm{Q})$ can be converted to its reduced form $\left(\mathrm{QH}_{2}\right)$ by the use of a reference molecule. Here, $\mathrm{RH}_{2}$ is the reference molecule. The model used was discussed in detail elsewhere $[12,13]$ and a brief review will be presented here. The difference between the electrode potential of two species 
<smiles>Oc1ccc(O)cc1</smiles><smiles>Oc1ccc(O)c(Cl)c1</smiles><smiles>Oc1ccc(O)c(O)c1</smiles><smiles>Oc1ccccc1O</smiles>
4<smiles>Oc1ccc2ccccc2c1O</smiles>

6<smiles>Oc1ccc(O)c2ccccc12</smiles><smiles>Cc1cc(O)ccc1O</smiles><smiles>Cc1cc(O)c(C)cc1O</smiles>

Fig. 1. Reduced forms of the studied molecules.

can be obtained from the change of Gibbs free energy of reaction (1):

$\Delta G^{\circ}=-n F\left(E_{\mathrm{Q}}^{\circ}-E_{\mathrm{R}}^{\circ}\right)$

where $n$ is number of electrons transferred and $F$ is the Faraday constant.

In order to calculate the standard electrode potential of a molecule, compared to SHE, more directly, the Gibbs energy change of the following reactions should be taken into account:

$\mathrm{Q}_{\text {(sol) }}+\mathrm{H}_{2 \text { (gas) }} \rightarrow \mathrm{QH}_{2 \text { (sol) }}$

The Gibbs energy change of the reaction (3) can be written in terms of these two half-reactions:

$\mathrm{Q}_{(\mathrm{sol})}+2 \mathrm{H}_{(\mathrm{sol})}^{+}+2 \mathrm{e}_{(\mathrm{gas})}^{-} \rightarrow \mathrm{QH}_{2(\mathrm{sol})}$

$1 / 2 \mathrm{H}_{2(\mathrm{gas})} \rightarrow H_{(\mathrm{sol})}^{+}+\mathrm{e}_{(\mathrm{gas})}^{-}$

The standard Gibbs energy of reaction (3), $\Delta G_{3}^{\circ}$, can be written as a sum of the Gibbs energy of reaction (4), $\Delta G_{4}^{\circ}$, and twice as much of the Gibbs energy of reaction (5), which is reported to be $4.36 \mathrm{eV}$ [2].

$\Delta G_{3}^{\circ}=\Delta G_{4}^{\circ}+2 \Delta G_{5}^{\circ}$

The two-electron standard electrode potential of molecule, $E_{2}^{\circ}$, can be obtained by the following equation $[2,13]$ :

$\Delta G_{3}^{\circ}=-n F E_{2}^{\circ}$

In this work, the internal energies are calculated by MP2 and MP3 using 6-31G(d,p) and 6-31+G(2d,p) basis sets, considering the size and type of the studied molecules (Fig. 1). The geometries are fully optimized at the level of MP2 and using 6-31G(d,p) basis set. The optimized structure was used for further calculations such as calculation of energies in the presence of solvent. Zero-point vibrational energies and thermal corrections together with entropy contributions were obtained using the HF/6-31G(d,p) geometries and scaled [16] frequencies. We have used PCM (DPCM or Tomasi) model of solvation [17] in order to calculate solvation energies. In order to build the cavity, we used the UAHF radii based on the united atom topological model which were optimized for the HF/631G(d) level of theory. Gaussian 98 has been employed for all calculations [18].

Table 1

Gas-phase Gibbs free energy, $\Delta G^{\circ}(\mathrm{g})$, and solvation energy, $\Delta G^{\circ}(\mathrm{s})$, of the studied quinone derivatives for both reduced $(\mathrm{QH} 2)$ and oxidised $(\mathrm{Q})$ forms together with the calculated two-electron electrode potentials of the studied molecules in $V$, and the experimental values

\begin{tabular}{|c|c|c|c|c|c|c|c|c|}
\hline \multirow[t]{2}{*}{$\mathrm{No}^{\mathrm{a}}$} & \multirow{2}{*}{$\frac{\Delta G^{\circ}(\mathrm{g}) \text { a.u. }}{\mathrm{b}}$} & \multirow{2}{*}{$\begin{array}{l}\Delta G^{\mathrm{o}}(\mathrm{g}) \text { a.u. } \\
\mathrm{Q}\end{array}$} & \multirow{2}{*}{$\begin{array}{l}\Delta G^{\circ}(\mathrm{s}) \mathrm{kJ} / \mathrm{mol} \\
\mathrm{QH}_{2}\end{array}$} & \multirow{2}{*}{$\begin{array}{l}\Delta G^{\circ}(\mathrm{s}) \mathrm{kJ} / \mathrm{mol} \\
\mathrm{Q}\end{array}$} & \multicolumn{3}{|c|}{$E_{2, \text { clac }}^{\circ}(V)$} & \multirow[t]{2}{*}{$E_{2, \text { exe }}^{\circ}(V)^{\mathrm{e}}$} \\
\hline & & & & & $\mathrm{MP}^{\mathrm{c}}$ & $\mathrm{MP}^{\mathrm{c}}$ & $\mathrm{MP}^{\mathrm{d}}$ & \\
\hline 1 & -381.52877 & -380.32324 & -52.1 & -30.9 & - & - & 0.690 & 0.700 \\
\hline 3 & -456.56116 & -455.36284 & -61.0 & -38.8 & 0.565 & 0.607 & 0.597 & 0.594 \\
\hline 4 & -381.53205 & -380.31178 & -40.2 & -38.6 & 0.766 & 0.799 & 0.789 & 0.792 \\
\hline 5 & -534.66806 & -533.48144 & -48.5 & -25.8 & 0.442 & 0.450 & 0.440 & 0.470 \\
\hline 8 & -459.87477 & -458.67572 & -45.1 & -23.5 & 0.631 & 0.614 & 0.604 & 0.590 \\
\hline $\mathrm{MAD}^{\mathrm{f}}$ & & & & & 0.026 & 0.019 & 0.015 & \\
\hline
\end{tabular}

a See Fig. 1 for the list of molecules.

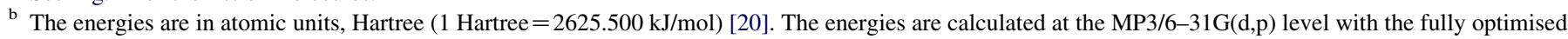
geometries obtained by MP2/6-31G(d,p).

c The calculated electrode potentials obtained using Eq. (2). Molecule 1 is the reference molecule and therefore, its electrode potential is excluded.

d The calculated electrode potentials obtained using Eq. (7).

e Experimental values are taken from reference [6].

${ }^{\mathrm{f}}$ Mean absolute deviations (MAD) or mean unsigned error of calculated $E_{2}^{\circ}$ from the experimental values. 


\section{Results and discussion}

Some quinone derivatives whose theoretical and experimental two-electron electrode potentials in aqueous were available to us, were chosen so that we could compare the MP3 results with those reported previously $[12,13]$.

Table 1 shows the calculated Gibbs free energy of molecules in both reduced and oxidised forms in the gas phase using ab initio calculations at the MP3 level and employing 6-31G(d,p) basis set. Solvation energies are computed using PCM method and the results are also shown in Table 1. Finally, the total change of Gibbs energy of the redox reaction (1), $\Delta G_{\mathrm{tot}}^{\circ}$, which is the sum of gas-phase energies and solvation energies [12,13], are calculated.

As discussed briefly in the previous section, the standard electrode potentials of quinone derivatives can be obtained using the total change of Gibbs energy of the redox reaction (1) along with the experimental electrode potential of the reference molecule $(0.700 \mathrm{~V})$ [6]. Table 1 presents the calculated electrode potentials of the studied molecules obtained with the MP2/6-311+G(2d,p) and MP3/6-31G(d,p) methods, together with the experimental values and those described earlier at lower levels of theory. Inspecting the results reveals that the calculated two-electron electrode potentials using MP3 are in good agreement with the experimental values. The discrepancy between theory and experiment, which is defined by mean absolute deviations (MAD) [2], is slightly less than $0.020 \mathrm{~V}$. The MP2 results, which are obtained in conjunction with the PCM model of solvation, are also in good agreement with the experimental results. The MP perturbation theory at the third order decreased the MAD by $0.002 \mathrm{~V}$.

Table 1 also presents MP3 direct calculation of twoelectron electrode potentials based on Eqs. (6) and (7) considering $\Delta G_{\mathrm{H}^{+}, \mathrm{gas}}^{\circ}=-6.28 \mathrm{kcal} / \mathrm{mol}[19]$ and $\Delta G_{\mathrm{H}^{+} \text {solv }}^{\circ}$ $=-258 \mathrm{kcal} / \mathrm{mol}$. It is worth noting that the experimental solvation energy of the proton is reported to be in the wide range of -254 to $-261 \mathrm{kcal} / \mathrm{mol}$ [19]. Our calculations of the electrode potentials in this case indicate that the solvation free energy of the proton is close to almost in the middle of the reported range. The discrepancy between theory and experiment is $0.018 \mathrm{~V}$.

\section{Conclusions}

This article extends our previous studies of the two-electron electrode potentials of some quinones by HF [12] and DFTB3LYP $[12,13]$ methods, to the same calculations but with the use of Møller-Plesset perturbation theory at the level of second and third corrections (MP2 and MP3). The mean absolute deviations (MAD) are reduced and therefore, in order to calculate the absolute standard electrode potentials, higher levels of theory can be important. There is still hope that calculation of electrode potentials in aqueous solution can be obtained by within $0.01 \mathrm{~V}$ error with the use of suitable level of theory and a compatible solvation model.

\section{Acknowledgements}

Research School of Chemistry, Australian National University is gratefully acknowledged for providing the visiting fellowship to MN. Generous allocation of computing time on the Australian National University Supercomputing Facility is also gratefully acknowledged.

\section{References}

[1] Y. Fu, L. Liu, H.-Z. Yu, Y. Wang, Q.-X. Guo, J. Am Chem. Soc. 127 (2005) 7227.

[2] P. Winget, C.J. Cramer, D.G. Truhlar, Theor. Chem. Acc. 112 (2004) 217.

[3] K. Wei, S.-W. Luo, Y. Fu, L. Liu, Q.-X Guo, J. Mol. Struct. (Theochem) 712 (2004) 197.

[4] J. Koyama, I. Morita, N. Kobayashi, T. Osakai, H. Hotta, J. Takayasu, H. Nishino, H. Tokuda, Cancer Lett. 212 (2004) 1.

[5] C.A. Reynolds, W.G. Richards, P.J. Goodford, J. Chem. Soc., Perkin Trans. II (1990) 551.

[6] H.S. Rzepa, G.A. Suner, J. Chem. Soc., Chem. Commun. (1993) 1743.

[7] C.A. Reynolds, W.G. Richards, P.J. Goodford, Anti-Cancer Drug Des. 1 (1987) 291.

[8] R.G. Compton, P.M. King, C.A. Reynolds, W.G. Richards, A.M. Waller, J. Electroanal. Chem. 258 (1989) 79.

[9] C.A. Reynolds, J. Am. Chem. Soc. 112 (1990) 7545.

[10] R. Compton, P.M. King, C.A. Reynolds, W.G. Richards, A.M. Waller, J. Electroanal. Chem. 258 (1989) 7545.

[11] S.G. Lister, C.A. Reynolds, W.G. Richards, Int. J. Quantum Chem. 41 (1992) 293.

[12] M. Namazian, H.A. Almodarresieh, J. Mol. Struct. (Theochem) 686 (2004) 97.

[13] M. Namazian, H.A. Almodarresieh, M.R. Noorbala, H.R. Zare, Chem. Phys. Lett. 396 (2004) 424.

[14] J.A. Pople, J.S. Binkley, R. Seeger, Int. J. Quantum Chem. Symp. 10 (1976) 1.

[15] J.A. Pople, R. Seeger, R. Krishnan, Int. J. Quantum Chem. Symp. 11 (1977) 149.

[16] A. Scott, L. Radom, J. Phys. Chem. 100 (1996) 16502.

[17] M. Cossi, V. Barone, R. Cammi, J. Phys. Lett. 255 (1996) 327.

[18] M.J. Frisch, G.W. Trucks, H.B. Schlegel, G.E. Scuseria, M.A. Robb, J.R. Cheeseman, V.G. Zakrzewski, J.A. Montgomery, Jr., R.E. Stratmann, J.C. Burant, S. Dapprich, J.M. Millam, A.D. Daniels, K.N. Kudin, M.C. Strain, O. Farkas, J. Tomasi, V. Barone, M. Cossi, R. Cammi, B. Mennucci, C. Pomelli, C. Adamo, S. Clifford, J. Ochterski, G.A. Petersson, P.Y. Ayala, Q. Cui, K. Morokuma, D.K. Malick, A.D. Rabuck, K. Raghavachari, J.B. Foresman, J. Cioslowski, J.V. Ortiz, B.B. Stefanov, G. Liu, A. Liashenko, P. Piskorz, I. Komaromi, R. Gomperts, R.L. Martin, D.J. Fox, T. Keith, M.A. Al-Laham, C.Y. Peng, A. Nanayakkara, C. Gonzalez, M. Challacombe, P.M.W. Gill, B. Johnson, W. Chen, M.W. Wong, J.L. Andres, C. Gonzalez, M. Head-Gordon, E.S. Replogle, J.A. Pople, Gaussian, Inc., Pittsburgh PA, 1998.

[19] Y.H. Jang, L.C. Sowers, T. Cagin, W.A. Goddard, J. Phys. Chem. A 105 (2001) 274.

[20] J.B. Foresman, A.E. Frisch, Exploring Chemistry With Electronic Structure Methods, Gaussian, Inc. Pittsburgh, PA, 1998. 